\title{
Adsorption Mechanism of Metalaxyl Pesticide in Pesticide/Heavy Metal Sediment Using Fractional Factorial Design/Fixed Effects Models
}

\author{
Jiawen Yang ${ }^{1,2}$, Wenwen Gu, ${ }^{1,2}$, Zhenhua Chu ${ }^{1,2}$, Yu Li ${ }^{1,2 *}$ \\ ${ }^{1}$ College of Environmental Science and Engineering, North China Electric Power University, Beijing, P. R. China \\ ${ }^{2} \mathrm{MOE}$ Key Laboratory of Resources and Environmental Systems Optimization, \\ North China Electric Power University, Beijing, P. R. China
}

Received: 31 December 2018

Accepted: 14 April 2019

\begin{abstract}
A resolution $\mathrm{V} 2^{10-3}$ fractional factorial design method was estimated to identify the main effect and second-order effects of pesticides and heavy metals concentrations in a composite contamination system on adsorption of sediment to metalaxyl, combined with a fixed effects model. It was found that contributions of the second-order interaction effects of the pollutant factor concentrations (79\%) was dominated in controlling metalaxyl adsorption to sediment in the system than that of the main effect $(21 \%)$, and the significant synergistic and antagonistic effects to metalaxyl adsorption were $47.93 \%$ and $52.07 \%$, respectively, indicating that metalaxyl adsorption was inhibited. Meanwhile, the main effect and second-order effects of the pollutant factor concentrations $(36.32 \%$ and $63.68 \%)$ in the synergies effects and $(6.81 \%$ and $93.19 \%)$ in the antagonistic effects were calculated, showing that more contribution was attributed from the second-order effects of pollutant factor concentrations to metalaxyl adsorption in the combined pesticide and heavy metal system.
\end{abstract}

Keywords: sediments, metalaxyl, pesticide, heavy metal, fractional factorial design

\section{Introduction}

As industry and agriculture have both continued to develop rapidly, pesticide consumption and human exposure to heavy metals in the environment have also increased $[1,2]$. The quantity of contaminants entering the environment has significantly increased, and environmental pollution can no longer be attributed to a single pollutant; rather, a variety of pollutants exist as mixed components in coexisting systems [3]. Compound

*e-mail: 731552195@qq.com pollution of pesticides and inorganic pollutants, represented in this study by heavy metals, is widespread in our environment.

Compound pollution refers to the contamination of the same medium (soil, water, atmosphere, biology) by multiple contaminants at the same time. These pollutants have long cycles and are hazardous and difficult to disaggregate. This is particularly true for organic pesticides and heavy metals, which accumulate chronically and become enriched in the human body via contaminated food consumption, resulting in serious harm to human health $[4,5]$; and heavy metals along with toxic agents organic in nature or phenolic 
compounds affecting the surface and soil waters [6]. While compound pollution by pesticides and heavy metals has become increasingly common in agroecosystems, it has only been studied in very general terms. As an urgent topic, compound pollution by pesticides and heavy metals has slowly gained popularity as a topic in agricultural environmental science research in recent years [7].

Sediment comprises small particles that move by fluid flow and eventually form a solid layer particle system at the bottom of water or other liquid. Sediments on natural surfaces and in water are important carriers, and a major sink, of many pollutants [8]. At present, combined pesticide and heavy metal pollution and the adsorption of pesticides in the water-sediment environment are important topics in environmental science [9-11], and recent research includes examinations of the distribution of pesticides and heavy metals in sediments in different regions [12-14], including the soil and water contamination caused by heavy metals in the different municipal waste landfill areas $[15,16]$, the mechanisms by which pollutants are adsorbed to sediments [17], and the mechanisms that control the adsorption of compound pollutants to sediment [18].

Studies of compound pollution by pesticides and heavy metals have mainly examined the effects of compound pollutants on soil quality; for example, the effects of pesticide and heavy metal compound pollution on soil enzymes [19,20], the effects of combined pesticide and heavy metal pollution on soil microbes [21-24], toxic effects on plants [25, 26], and the effects of interactions between pesticides and heavy metals. At present, most studies of compound pollution have examined two different pollutants, and few studies have examined compound pollution from three or more different pollutants. Furthermore, there have been few detailed studies of the mechanisms that influence the effects of interactions among different pollutants and toxicity at different pollutant concentrations. $\mathrm{Li}$ et al. [27] used the resolution IV $2^{10-5}$ fractional factorial design method to study the composite contamination of zinc and 10 pollutants on sediments, and focused on the interaction effects among the concentrations of multiple pollutant factors. They used complete folding and a block design to help distinguish the link between the main effect and second-order interaction effects, but failed to clearly distinguish the links between the second-order interaction effects.

In this study, we used a resolution $\mathrm{V} 2^{10-3}$ fractional factorial design method to examine the characteristics of metalaxyl adsorption to superficial sediments in a pesticide (metalaxyl, atrazine, dimethoate, prometryn, and malathion)/heavy metal (lead, zinc, copper, nickel, and cadmium) composite contamination system. We also attempted to eliminate the confounding effects between the second-order interaction effects and identify the effects of each second-order interaction on the target pollutants using the resolution $\mathrm{V} 2^{10-3}$ method. We then compared the results with those from a resolution IV $2^{10-5}$ fractional factorial design method. This is the first time that the pesticide metalaxyl has been used as the target pollutant in studies of a composite sediment system contaminated with pesticides and heavy metals. The results of this study therefore will provide information about the mechanisms that govern combined pollution from pesticide and heavy metal compounds.

\section{Material and Methods}

\section{Sediment Sample Collection and Pretreatment}

We collected sediment samples from the Songhua River in Jilin, China. Refer to the "Water and Wastewater Monitoring and Analysis Method" during the sampling process. Specific steps were as follows: samples were collected to a depth of $5 \mathrm{~cm}$ below the surface using a digging-type sampler. At each sampling point four samples, spaced at $20 \mathrm{~cm}$ intervals, were collected and combined to form a uniform sample. After the sample collection was completed, we removed the non-sediment components (for instance stones, garbage, biological debris, etc.), the river water was filtered and packaged with the sediment samples in a sampling bag to ensure that no leakage or contamination occurred during transportation. In the end, the samples were natural withering, ground, and sieved in the laboratory, and the finished sediment samples were placed in a jar for sealing.

\section{Experimental Methods and Design}

We selected a total of 10 pollutants comprising five pesticides, namely metalaxyl (marked A), atrazine (B), dimethoate (C), prometryn (D), and malathion (E), and five heavy metals, namely lead $(\mathrm{F})$, zinc $(\mathrm{G})$, copper $(\mathrm{H})$, nickel $(\mathrm{J})$, and cadmium $(\mathrm{K})$, as the experimental factors. In this study, we chose the pesticide metalaxyl as the target pollutant and we examined the main effects and second-order interaction effects of the pollutant factor concentrations on the adsorption of the target pollutant to the sediment. The pesticide concentrations were between 10 and $25 \mu \mathrm{mol} / \mathrm{L}$ and the heavy metal concentrations were between 60 and $150 \mu \mathrm{mol} / \mathrm{L}$. In this experiment we used a resolution $V 2^{10-3}$ fractional factorial experiment with a minimum low-order mixture, and set a unit of 128 parallel to the sample, and processed a total of 384 groups. Using the principles of fractional factorial design in Minitab, the interactions of metalaxyl (A), atrazine (B), dimethoate (C), prometryn (D), malathion (E), zinc (G), and lead (F), the form of the generating element, and the concentrations of copper $(\mathrm{H})$, nickel $(\mathrm{J})$ and cadmium $(\mathrm{K})$ were determined as follows: $\mathrm{F}=\mathrm{CABK}, \mathrm{G}=\mathrm{ABED}$, and $\mathrm{J}=\mathrm{CBEH}$. Again, following the principles of fractional factorial design in Minitab, the interactions of dimethoate (C), 
atrazine (B), malathion (E), prometryn (D), cadmium $(\mathrm{K})$, lead $(\mathrm{F})$ and zinc $(\mathrm{G})$, the form of the generating, and the concentrations of metalaxyl (A) were chosen as follows: $\mathrm{A}=\mathrm{CBKF}=\mathrm{BEDG}$. The mixed solution contained 10 pollutants at different concentrations. The configured 384 solutions were added to a conical flask that contained a sediment sample $(0.5000 \mathrm{~g} \pm 0.0001 \mathrm{~g})$. The remaining 128 mixed solutions were placed into dry clean conical flasks without sediment. Each solution was sealed with a cotton swab and oscillated at room temperature for $48 \mathrm{~h}$, after which the solutions were passed through filter paper with a pore size of $0.22 \mu \mathrm{m}$. The initial pesticide and heavy metal concentrations and the concentrations in the solution were measured by high-performance liquid chromatography and flame atomic absorption spectrophotometry. Finally, the

Table 1. Adsorption of the sediment to metalaxyl in a pesticide/heavy metal coexistence system $(\mu \mathrm{mol} / \mathrm{g})$.

\begin{tabular}{|c|c|c|c|c|c|c|c|}
\hline NO. & $\begin{array}{c}\text { Adsorption of } \\
\text { metalaxyl }\end{array}$ & NO. & $\begin{array}{c}\text { Adsorption of } \\
\text { metalaxyl }\end{array}$ & NO. & $\begin{array}{l}\text { Adsorption of } \\
\text { metalaxyl }\end{array}$ & NO. & $\begin{array}{c}\text { Adsorption of } \\
\text { metalaxyl }\end{array}$ \\
\hline 1 & 1.062 & 33 & 0.378 & 65 & 0.248 & 97 & 0.084 \\
\hline 2 & 0.035 & 34 & 4.645 & 66 & 0.257 & 98 & 0.581 \\
\hline 3 & 0.045 & 35 & 0.056 & 67 & 0.117 & 99 & 0.052 \\
\hline 4 & 0.672 & 36 & 0.037 & 68 & 0.471 & 100 & 0.732 \\
\hline 5 & 0.041 & 37 & 0.043 & 69 & 0.240 & 101 & 0.276 \\
\hline 6 & 0.063 & 38 & 0.058 & 70 & 0.151 & 102 & 1.868 \\
\hline 7 & 0.145 & 39 & 0.119 & 71 & 0.153 & 103 & 0.272 \\
\hline 8 & 0.119 & 40 & 0.203 & 72 & 0.654 & 104 & 0.188 \\
\hline 9 & 0.073 & 41 & 0.248 & 73 & 0.145 & 105 & 0.419 \\
\hline 10 & 0.231 & 42 & 0.320 & 74 & 0.896 & 106 & 0.378 \\
\hline 11 & 3.878 & 43 & 0.186 & 75 & 0.974 & 107 & 0.032 \\
\hline 12 & 0.173 & 44 & 0.620 & 76 & 0.695 & 108 & 0.587 \\
\hline 13 & 1.602 & 45 & 0.669 & 77 & 0.026 & 109 & 0.117 \\
\hline 14 & 0.168 & 46 & 0.246 & 78 & 0.032 & 110 & 0.019 \\
\hline 15 & 0.108 & 47 & 0.348 & 79 & 0.155 & 111 & 0.026 \\
\hline 16 & 1.848 & 48 & 0.119 & 80 & 0.261 & 112 & 0.512 \\
\hline 17 & 0.112 & 49 & 0.045 & 81 & 0.376 & 113 & 0.073 \\
\hline 18 & 0.369 & 50 & 0.084 & 82 & 0.035 & 114 & 0.048 \\
\hline 19 & 2.676 & 51 & 0.099 & 83 & 0.004 & 115 & 0.181 \\
\hline 20 & 0.168 & 52 & 0.231 & 84 & 0.292 & 116 & 0.620 \\
\hline 21 & 0.274 & 53 & 0.961 & 85 & 0.138 & 117 & 0.229 \\
\hline 22 & 0.004 & 54 & 0.017 & 86 & 0.572 & 118 & 0.078 \\
\hline 23 & 0.006 & 55 & 0.009 & 87 & 0.099 & 119 & 0.479 \\
\hline 24 & 0.216 & 56 & 0.324 & 88 & 1.324 & 120 & 0.520 \\
\hline 25 & 0.395 & 57 & 0.469 & 89 & 0.309 & 121 & 0.099 \\
\hline 26 & 0.978 & 58 & 0.108 & 90 & 0.495 & 122 & 0.667 \\
\hline 27 & 0.043 & 59 & 0.587 & 91 & 0.436 & 123 & 0.641 \\
\hline 28 & 0.566 & 60 & 0.173 & 92 & 0.212 & 124 & 0.045 \\
\hline 29 & 0.013 & 61 & 0.089 & 93 & 0.110 & 125 & 0.073 \\
\hline 30 & 0.084 & 62 & 0.298 & 94 & 4.438 & 126 & 2.965 \\
\hline 31 & 0.082 & 63 & 0.147 & 95 & 1.240 & 127 & 0.112 \\
\hline 32 & 0.009 & 64 & 0.121 & 96 & 0.829 & 128 & 0.078 \\
\hline
\end{tabular}


pollutant adsorption was determined by differential subtraction [28]. The adsorption of the sediment to metalaxyl in pesticide/heavy metal coexistence system was shown in Table 1.

In line with the principles of the resolution $\mathrm{V} 2^{10-3}$ fractional factorial design method, the generators of the main effects and the second-order interaction effects and the aliases of the main effects and the second-order interaction effects were determined as follows:

Aliases of the second-order interaction effects: $\mathrm{CA}=\mathrm{BKF}=\mathrm{DHGJ}, \mathrm{CB}=\mathrm{BGH}=\mathrm{AKF}, \mathrm{CE}=\mathrm{BHJ}$ $=\mathrm{DKFG}, \mathrm{CD}=\mathrm{AHGJ}=\mathrm{EKFG}, \mathrm{CH}=\mathrm{BEJ}=\mathrm{ADGJ}$, $\mathrm{CK}=\mathrm{ABF}=\mathrm{EDFG}, \mathrm{CF}=\mathrm{ABK}=\mathrm{EDKG}, \mathrm{CG}=\mathrm{ADHJ}$ $=\mathrm{EDKF}, \mathrm{CJ}=\mathrm{BEH}=\mathrm{ADHG}, \mathrm{AB}=\mathrm{CKF}=\mathrm{EDG}, \mathrm{AE}$ $=\mathrm{BDG}=\mathrm{HKFJ}, \mathrm{AD}=\mathrm{BEG}=\mathrm{CHGJ}, \mathrm{AH}=\mathrm{CDGJ}$ $=\mathrm{EKFJ}, \mathrm{AK}=\mathrm{CBF}=\mathrm{EHFJ}, \mathrm{CJ}=\mathrm{BEH}=\mathrm{ADHG}, \mathrm{AB}$ $=\mathrm{CKF}=\mathrm{EDG}, \mathrm{AE}=\mathrm{BDG}=\mathrm{HKFJ}, \mathrm{AD}=\mathrm{BEG}$ $=\mathrm{CHGJ}, \mathrm{AH}=\mathrm{CDGJ}=\mathrm{EKFJ}, \mathrm{AK}=\mathrm{CBF}=\mathrm{EHFJ}$, $\mathrm{AF}=\mathrm{CBK}=\mathrm{EHKJ}, \mathrm{AG}=\mathrm{BED}=\mathrm{CDHJ}, \mathrm{AJ}=\mathrm{CDHG}$ $=\mathrm{EHKF}, \mathrm{BE}=\mathrm{CHJ}=\mathrm{ADG}, \mathrm{BD}=\mathrm{AEG}, \mathrm{BH}=\mathrm{CEJ}, \mathrm{BK}$ $=\mathrm{CAF}, \mathrm{BF}=\mathrm{CAK}, \mathrm{BG}=\mathrm{AED}, \mathrm{BJ}=\mathrm{CEH}, \mathrm{ED}=\mathrm{ABG}$ $=\mathrm{CKFG}, \mathrm{EH}=\mathrm{CBJ}=\mathrm{AKFJ}, \mathrm{EK}=\mathrm{CDFG}=\mathrm{AHFJ}$, $\mathrm{EF}=\mathrm{CDKG}=\mathrm{AHKJ}, \mathrm{EG}=\mathrm{ABD}=\mathrm{CDKF}, \mathrm{EJ}=\mathrm{CBH}$ $=\mathrm{AHKF}, \mathrm{DH}=\mathrm{CAGJ}, \mathrm{DK}=\mathrm{CEFG}, \mathrm{DF}=\mathrm{CEKG}, \mathrm{DG}$ $=\mathrm{ABE}=\mathrm{CAHJ}=\mathrm{CEKF}, \mathrm{DJ}=\mathrm{CAHG}, \mathrm{HK}=\mathrm{AEFJ}, \mathrm{HF}$ $=\mathrm{AEKF}, \mathrm{HG}=\mathrm{CADJ}, \mathrm{HJ}=\mathrm{CBE}=\mathrm{CADG}=\mathrm{AEKF}$, $\mathrm{KF}=\mathrm{CAB}=\mathrm{CEDG}=\mathrm{AEHJ}, \mathrm{KG}=\mathrm{CEDF}, \mathrm{KJ}=\mathrm{AEHF}$, $\mathrm{FG}=\mathrm{CEDK}, \mathrm{FJ}=\mathrm{AEHK}, \mathrm{GJ}=\mathrm{CADH}$.

This analysis indicated that without considering the role of third-order interaction effects, the resolution $\mathrm{V} 2^{10-3}$ fractional factorial design could be used to identify the confounding structure of the interactions, to completely distinguish the main effects from the second-order interaction effects using the resolution $\mathrm{V}$ $2^{10-3}$ fractional factorial design method, and to estimate the response value of the main effects and the secondorder interaction effects. The adsorption mechanisms of target pollutants when influenced by the main effects and second-order interaction effects were also examined.

\section{Results and Discussion}

\section{Data Processing and Analysis of the Resolution V $2^{10-3}$ Fractional Factorial Design Method}

We used the design of experiments module in Minitab software to: (1) test the fit of the fixed effects model of the resolution $\mathrm{V} 2^{10-3}$ fractional factorial design method, (2) determine the relationships between metalaxyl adsorption onto the surficial sediments in the pesticide/heavy metal composite contamination system and the concentrations of the 10 pollutant factors, and (3) estimate the main effect and the second-order interaction effects of the pollutant factor concentrations on metalaxyl sorption to surficial sediments in the pesticide/heavy metal system. The fractional factorial design method artificially controls the pollutant factor concentrations at fixed levels, which means that we can reasonably analyze the main effect and the second-order interaction effects of the pollutant factor concentrations in the composite system on the metalaxyl adsorption capacity of the sediment with the fixed effects model. We tested the fit, assuming a normal distribution, independent of the residuals, and homogeneity of the variance, before using a fixed effects model to examine the main effect and the second-order interaction effects of the pollutant factor concentrations in the pesticide/ heavy metal combined system. We used analysis of variance (significance level of 0.05 ) to analyze the main effect and the second-order interaction effect of the concentrations of each pollutant factor in the pesticide/ heavy metal combined system when the significant impact factors were filtered out, and determined whether the main effect and the second-order interaction effect of the concentrations of each pollutant factor had a significant effect on the adsorption of sediment to metalaxyl.

\section{Testing the Fit of the Fixed Effects Model of Metalaxyl Adsorption}

The accuracy of the fixed effect model was verified by testing the fit. We can assess the rationality of the model by checking if the model residuals conform to the distribution law. The residuals of a reasonable model should be scattered irregularly. The model test results calculated with the residual test module in Minitab are shown in Fig. 1.

The fact that the residuals were normally distributed in the columnar plot (Fig. 1) shows that there were no abnormal trends in the residuals and that the sample data did not deviate from the normal distribution. Examination of the relationship between the residuals of the experimental data and the model fitting values showed that the residual points were irregularly distributed, which confirms that the homogeneity hypothesis of the model was satisfied. The relationship between the residuals and the experimental sequence shows that the residuals did not change with changes in the sequence of the experiment, and so proved the independence of the model. This analysis of the residuals showed that the fixed effect model was suitable for the factorial experiment design in this study.

\section{Analysis of Variance and Estimates of Effects by the Fixed Effect Model}

We carried out analysis of variance of the main effect and the second-order interaction effects of the pollutant factor concentrations on the capacity of sediment to adsorb metalaxyl using the fixed effect model with the resolution $\mathrm{V} 2^{10-3}$ fractional factorial design method. The results of this analysis are presented in Fig. 2. Estimates of the effects of the main effect and the second-order interaction effects of the pollutant factor concentrations on the capacity of the sediment to adsorb metalaxyl are presented in Table 2 . 


\section{Residual plots of the adsorption capacity of metalaxyl}
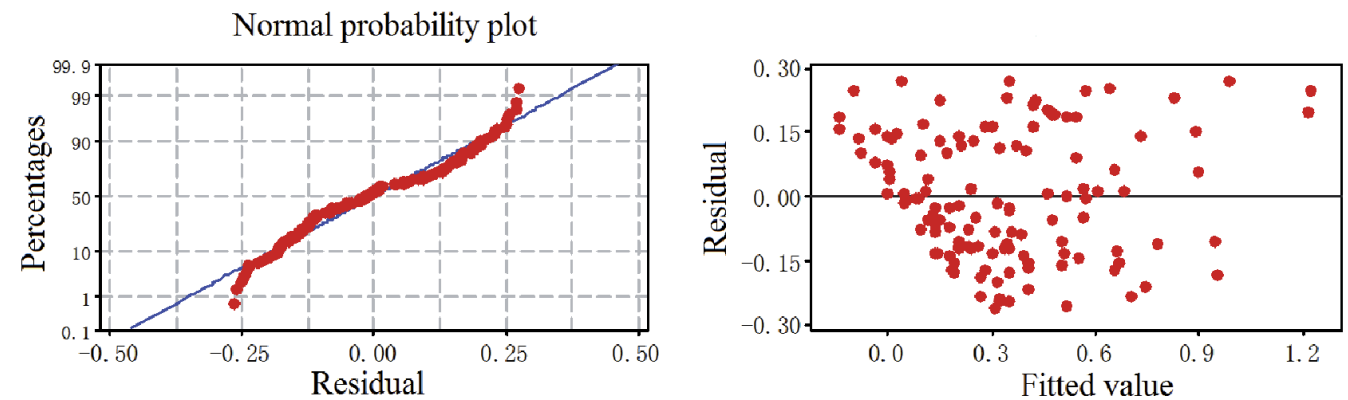

Histogram
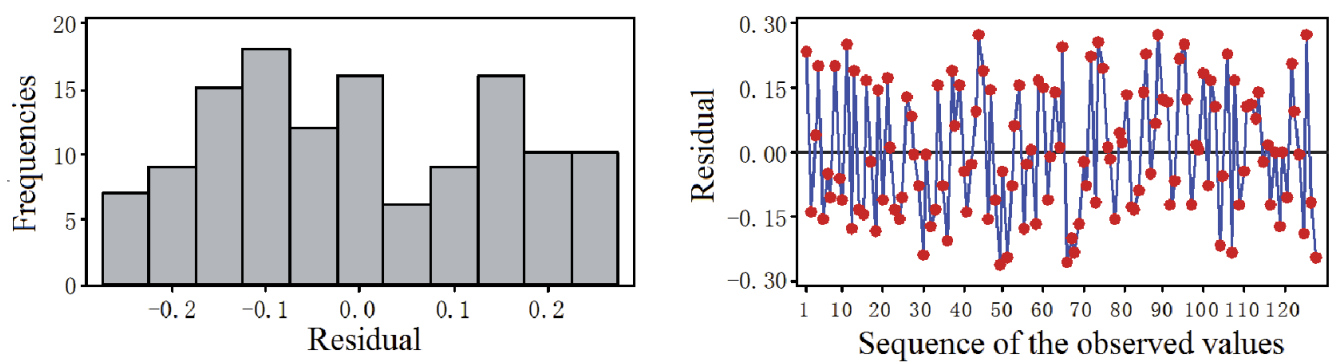

Fig. 1. Fit testing residual plots of the fixed effects model of adsorption capacity of the sediment to metalaxyl.

The analysis of variance results show that the resolution $\mathrm{V} 2^{10-3}$ fractional factorial design method estimated the degrees of freedom (DF) of the secondorder effect at 45 , higher than IV resolution, which can provide enough information to distinguish the alias of the second-order interaction effects. The $\mathrm{P}$ values of the main effect and the second-order interaction effects were both significantly lower than the significance level of 0.05 , indicating that the main effect and the second-order interaction effects of the pollutant factor concentrations had a significant effect on adsorption of sediment to metalaxyl. To analyze the characteristics of the composite contamination, we had to screen out the specific main effect and the second-order interaction effects.

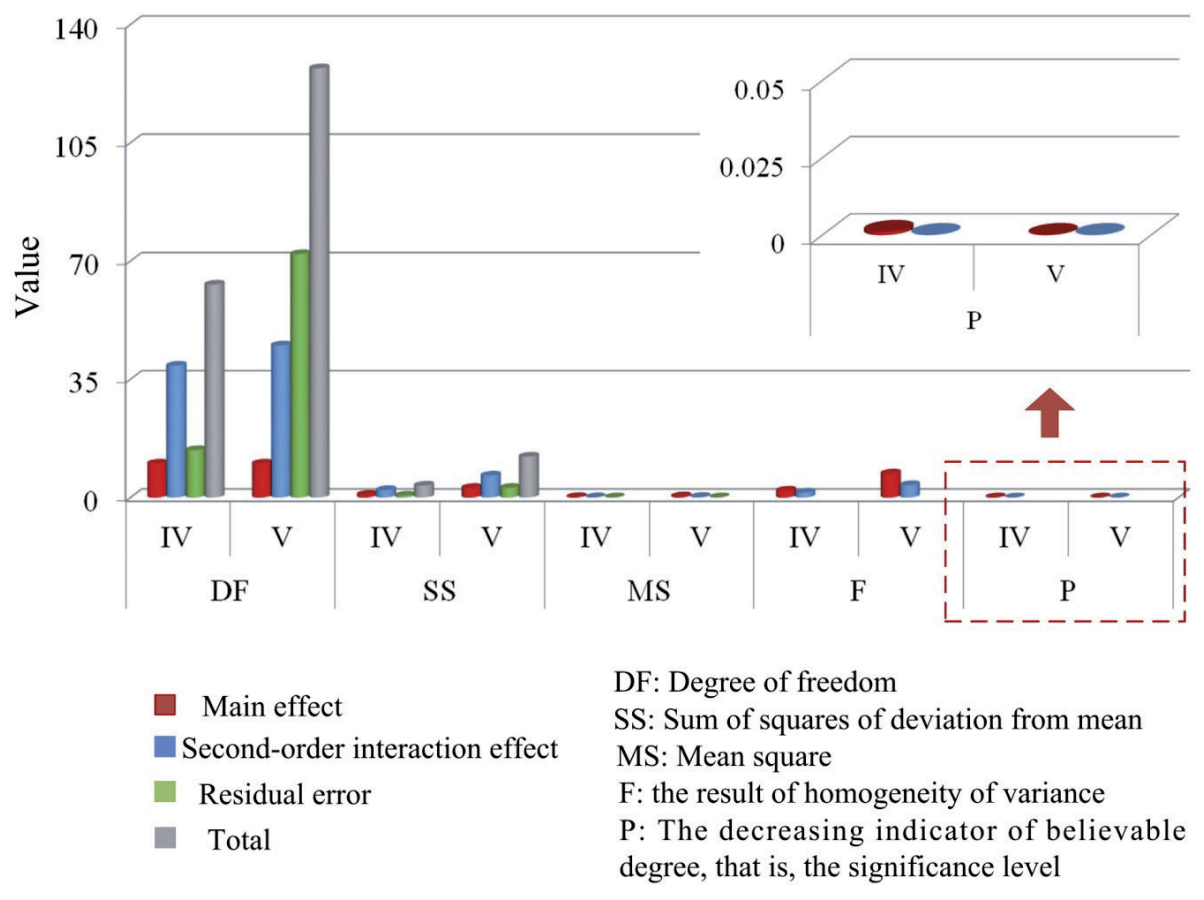

Fig. 2. Schematic diagram of analysis of variance of the main effect and the second-order interaction effect of the effect of the pollutant factor concentrations on the adsorption capacity of the sediment to metalaxyl. 
Table 2. Estimates of the effects of main effect and the second-order interaction effect of pollutant fact concentrations on adsorption capacities of the sediment to metalaxyl in a pesticide/heavy metal coexistence system and T-test for multiple linear regression Equation 1.

\begin{tabular}{|c|c|c|c|c|c|c|c|}
\hline \multirow{2}{*}{ Factor } & \multirow{2}{*}{ Coefficient } & \multicolumn{2}{|c|}{ Estimate of effect } & \multicolumn{2}{|c|}{$\mathrm{T}$} & \multicolumn{2}{|c|}{$\mathrm{P}$} \\
\hline & & IV & V & IV & $\mathrm{V}$ & IV & $\mathrm{V}$ \\
\hline Constant & 0.01754 & & 0.33937 & 9.65 & 0.00 & 0.000 & \\
\hline Dimethoate & -0.01975 & -0.01195 & -0.03949 & -0.24 & -1.13 & 0.813 & 0.264 \\
\hline Metalaxyl & 0.12083 & 0.04666 & 0.24166 & 0.94 & 6.89 & 0.363 & 0.000 \\
\hline Atrazine & -0.00497 & -0.04301 & -0.00995 & -0.87 & -0.28 & 0.401 & 0.778 \\
\hline Malathion & -0.01340 & -0.10631 & -0.02681 & -2.14 & -0.76 & 0.050 & 0.447 \\
\hline Prometryn & 0.00466 & 0.02468 & 0.00932 & 0.50 & 0.27 & 0.627 & 0.791 \\
\hline $\mathrm{Cu}$ & 0.06311 & -0.15632 & 0.12623 & -3.15 & 3.60 & 0.007 & 0.001 \\
\hline $\mathrm{Cd}$ & -0.02052 & -0.08946 & -0.04105 & -1.80 & -1.17 & 0.093 & 0.246 \\
\hline $\mathrm{Pb}$ & -0.03745 & -0.01315 & -0.07489 & -0.27 & -2.13 & 0.795 & 0.036 \\
\hline $\mathrm{Zn}$ & -0.01741 & -0.00118 & -0.03483 & -0.02 & -0.99 & 0.981 & 0.324 \\
\hline $\mathrm{Ni}$ & -0.02035 & -0.00651 & -0.04071 & -0.13 & -1.16 & 0.898 & 0.250 \\
\hline Dimethoate*Metalaxyl & -0.07692 & -0.03755 & -0.15383 & -0.76 & -4.38 & 0.462 & 0.000 \\
\hline Dimethoate*Atrazine & -0.00145 & -0.04893 & -0.00290 & -0.99 & -0.08 & 0.341 & 0.934 \\
\hline Dimethoate*Malathion & 0.03872 & 0.03989 & 0.07744 & 0.80 & 2.21 & 0.435 & 0.031 \\
\hline Dimethoate*Prometryn & -0.00512 & -0.04413 & -0.01024 & -0.89 & -0.29 & 0.389 & 0.771 \\
\hline Dimethoate $* \mathrm{Cu}$ & 0.01580 & 0.03202 & 0.03161 & 0.65 & 0.90 & 0.529 & 0.371 \\
\hline Dimethoate*Cd & -0.01017 & -0.00778 & -0.02034 & -0.16 & -0.58 & 0.878 & 0.564 \\
\hline Dimethoate* $\mathrm{Pb}$ & -0.00215 & -0.01401 & -0.00430 & -0.28 & -0.12 & 0.782 & 0.903 \\
\hline Dimethoate*Zn & -0.04137 & -0.04991 & -0.08273 & -1.01 & -2.36 & 0.332 & 0.021 \\
\hline Dimethoate*Ni & -0.02812 & 0.04826 & -0.05624 & 0.97 & -1.60 & 0.347 & 0.113 \\
\hline Metalaxyl*Atrazine & -0.01852 & -0.05982 & -0.03704 & -1.21 & -1.06 & 0.248 & 0.295 \\
\hline Metalaxyl*Malathion & 0.00013 & 0.02614 & 0.00025 & 0.53 & 0.01 & 0.607 & 0.994 \\
\hline Metalaxyl*Prometryn & 0.01918 & -0.01673 & 0.03836 & -0.34 & 1.09 & 0.741 & 0.278 \\
\hline Metalaxyl*Cu & 0.01880 & -0.04991 & 0.03760 & -1.01 & 1.07 & 0.331 & 0.287 \\
\hline Metalaxyl*Cd & -0.00511 & & -0.01023 & & -0.29 & & 0.771 \\
\hline Metalaxyl $* \mathrm{~Pb}$ & -0.05403 & & -0.10806 & & -3.08 & & 0.003 \\
\hline Metalaxyl*Zn & 0.01737 & 0.01439 & 0.03474 & 0.29 & 0.99 & 0.776 & 0.325 \\
\hline Metalaxyl*Ni & 0.03903 & 0.04036 & 0.07806 & 0.81 & 2.22 & 0.430 & 0.029 \\
\hline Atrazine*Malathion & -0.04859 & -0.09560 & -0.09717 & -1.93 & -2.77 & 0.075 & 0.007 \\
\hline Atrazine*Prometryn & -0.06514 & -0.00795 & -0.13027 & -0.16 & -3.71 & 0.875 & 0.000 \\
\hline Atrazine $* \mathrm{Cu}$ & 0.05095 & 0.11765 & 0.10190 & 2.37 & 2.90 & 0.033 & 0.005 \\
\hline Atrazine*Cd & 0.04105 & 0.03835 & 0.08210 & 0.77 & 2.34 & 0.452 & 0.022 \\
\hline Atrazine $* \mathrm{~Pb}$ & 0.05485 & 0.00133 & 0.10969 & 0.03 & 3.13 & 0.979 & 0.003 \\
\hline Atrazine*Zn & 0.00636 & 0.01411 & 0.01273 & 0.28 & 0.36 & 0.780 & 0.718 \\
\hline Atrazine*Ni & -0.01081 & 0.01767 & -0.02163 & 0.36 & -0.62 & 0.727 & 0.540 \\
\hline Malathion*Prometryn & -0.00148 & 0.06550 & -0.00297 & 1.32 & -0.08 & 0.208 & 0.933 \\
\hline Malathion* $\mathrm{Cu}$ & 0.05218 & 0.05599 & 0.10436 & 1.13 & 2.97 & 0.278 & 0.004 \\
\hline Malathion*Cd & -0.02195 & 0.08947 & -0.04391 & 1.80 & -1.25 & 0.093 & 0.215 \\
\hline
\end{tabular}




\begin{tabular}{|c|c|c|c|c|c|c|c|}
\hline Malathion*Pb & -0.0298 & -0.00202 & -0.05961 & -0.04 & -1.70 & 0.968 & 0.094 \\
\hline Malathion*Zn & -0.04479 & & -0.08958 & & -2.55 & 0.013 \\
\hline Malathion*Ni & 0.02924 & & 0.05849 & & 1.67 & 0.100 \\
\hline Prometryn*Cu & -0.02038 & -0.16566 & -0.04076 & -3.34 & -1.16 & 0.005 & 0.249 \\
\hline Prometryn*Cd & -0.00678 & 0.03540 & -0.01356 & 0.71 & -0.39 & 0.487 & 0.700 \\
\hline Prometryn*Pb & 0.03091 & 0.00019 & 0.06181 & 0.00 & 1.76 & 0.997 & 0.082 \\
\hline Prometryn*Zn & -0.05667 & -0.01335 & -0.11334 & -0.27 & -3.23 & 0.792 & 0.002 \\
\hline Prometryn*Ni & -0.03913 & -0.01227 & -0.07825 & -0.25 & -2.23 & 0.808 & 0.029 \\
\hline $\mathrm{Cu} * \mathrm{Cd}$ & -0.04535 & -0.05609 & -0.09069 & -1.13 & -2.58 & 0.277 & 0.012 \\
\hline $\mathrm{Cu} * \mathrm{~Pb}$ & -0.04076 & -0.02250 & -0.08152 & -0.45 & -2.32 & 0.657 & 0.023 \\
\hline $\mathrm{Cu} * \mathrm{Zn}$ & -0.01648 & 0.01201 & -0.03296 & 0.24 & -0.94 & 0.812 & 0.351 \\
\hline $\mathrm{Cu} * \mathrm{Ni}$ & -0.02651 & 0.02238 & -0.05303 & 0.45 & -1.51 & 0.659 & 0.135 \\
\hline $\mathrm{Cd} * \mathrm{~Pb}$ & -0.00084 & & -0.00169 & & -0.05 & & 0.962 \\
\hline $\mathrm{Cd} * \mathrm{Zn}$ & 0.01187 & 0.06035 & 0.02374 & 1.22 & 0.68 & 0.244 & 0.501 \\
\hline $\mathrm{Cd} * \mathrm{Ni}$ & -0.00747 & 0.05347 & -0.01494 & 1.08 & -0.43 & 0.299 & 0.672 \\
\hline $\mathrm{Pb} * \mathrm{Zn}$ & 0.00353 & -0.08840 & 0.00705 & -1.78 & 0.20 & 0.096 & 0.841 \\
\hline $\mathrm{Pb} * \mathrm{Ni}$ & -0.01666 & -0.16056 & -0.03332 & -3.24 & -0.95 & 0.006 & 0.345 \\
\hline $\mathrm{Zn} * \mathrm{Ni}$ & 0.04567 & & 0.09134 & & 2.60 & & 0.011 \\
\hline
\end{tabular}

As shown in Table 2, metalaxyl, as the main effect, had a significant synergistic effect on the absorption of the sediment to metalaxyl; copper and lead were the only heavy metals to have a significant effect on the absorption of sediment to the metalaxyl. The $\mathrm{P}$ value was less than 0.05 for the second-order effects of 17 combinations of pollutant factor concentrations, which showed that the second-order effects had an important influence on the absorption of sediment to the metalaxyl. In descending order, the second-order interaction effects of the concentrations of dimethoate*metalaxyl, atrazine*prometryn, prometryn*zinc, atrazine*lead, metalaxyl*lead, malathion*copper, atrazine*copper, atrazine*malathion, zinc*nickel, copper*cadmium, malathion*zinc, dimethoate*zinc, atrazine*cadmium, copper*lead, prometryn*nickel, metalaxyl*nickel, and dimethoate*malathion pollutant factors had significant effects on metalaxyl adsorption on the sediment. The second-order interaction effects of various combinations of pollutant factors, namely, listed in decreasing order - dimethoate*metalaxyl, atrazine*prometryn, prometryn*zinc, metalaxyl*lead, atrazine*copper, atrazine*malathion, copper*cadmium, malathion*zinc, dimethoate*zinc, copper*lead, and prometryn*nickel - had significant antagonistic effects on the adsorption of metalaxyl on the sediment. Various other combinations of the pollutant factors, namely (in decreasing order), atrazine*lead, malathion*copper, zinc*nickel, atrazine*cadmium, metalaxyl*nickel, and dimethoate*malathion, had second-order interaction effects with significant synergistic effects on metalaxyl adsorption on the sediment.

Echeverría et al. [29] measured the effects of single metals on the adsorption of other metal ions. Results showed that lead and copper inhibited the adsorption of nickel, zinc, and cadmium. This inhibitory effect may help to explain why, as the main effect, the lead and copper concentration factors had significant synergistic/ antagonistic effects on the adsorption of metalaxyl on the sediment. Zhang et al. [30] studied the adsorption behavior at the soil-water interface when influenced by lead, zinc and copper, and also the competitive adsorption and desorption behaviors of copper and lead in single adsorption and binary metal combined systems. The results showed that the physical and chemical properties of soil affected the adsorption capacity of the metals, both in the single and the binary metal combined system, and the soil had a greater capacity to adsorb lead than copper. In the system with two metals, the presence of both metal ions affected the total adsorption by the two metals, which was manifested as competitive adsorption between the metal ions. Therefore, the different physical and chemical properties of different pesticides and heavy metals may help to explain the variable sediment adsorption capacities of pesticides and heavy metals in the heavy metal/pesticide combined system. 
Table 3. Composite contamination characteristics of pollutant factors concentration to absorption of metaxyl in resolution IV of $2^{10-5 /}$ resolution $\mathrm{V}$ of $2^{10-3}$ fractional factorial design method.

\begin{tabular}{|c|c|c|c|c|c|c|}
\hline & & 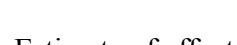 & & Rate of co & bution (\%) & \\
\hline & 1 actur t s & & Synergism & Synergism $^{\text {a }}$ & Antagonism & Antagonism ${ }^{\mathrm{a}}$ \\
\hline & $\mathrm{Cu}$ & -0.15632 & & & 0.260451 & \\
\hline & Atrazine ${ }^{*} \mathrm{Cu}$ & 0.11765 & 0.196021 & & & \\
\hline Resolution IV & Prometryn $* \mathrm{Cu}$ & -0.16566 & & & 0.276013 & \\
\hline & $\mathrm{Pb} * \mathrm{Ni}$ & -0.16056 & & & 0.267515 & \\
\hline & Total & 0.60019 & 0.196021 & & 0.803979 & \\
\hline & Metalaxyl & 0.24166 & 11.436224 & 10.528379 & & \\
\hline & $\mathrm{Cu}$ & 0.12623 & 5.973660 & 5.499451 & & \\
\hline & $\mathrm{Pb}$ & -0.07489 & & & 3.544065 & 3.262726 \\
\hline & Dimethoate*Metalaxyl & -0.15383 & & & 7.279791 & 6.701898 \\
\hline & Dimethoate*Malathion & 0.07744 & 3.664741 & 3.373822 & & \\
\hline & Dimethoate*Zn & -0.08273 & & & 3.915083 & 3.604290 \\
\hline & Metalaxyl*Pb & -0.10806 & & & 5.113790 & 4.707840 \\
\hline & Metalaxyl*Ni & 0.07806 & 3.694081 & 3.400833 & & \\
\hline & Atrazine*Malathion & -0.09717 & & & 4.598435 & 4.233397 \\
\hline & Atrazine*Prometryn & -0.13027 & & & 6.164847 & 5.675461 \\
\hline & Atrazine ${ }^{*} \mathrm{Cu}$ & 0.10190 & 4.822276 & 4.439468 & & \\
\hline & Atrazine* $\mathrm{Cd}$ & 0.08210 & 3.885269 & 3.576843 & & \\
\hline & Atrazine $* \mathrm{~Pb}$ & 0.10969 & 5.190927 & 4.778854 & & \\
\hline & Malathion* $\mathrm{Cu}$ & 0.10436 & 4.938692 & 4.546643 & & \\
\hline NCSOItution & Malathion*Zn & -0.08958 & & & 4.239249 & 3.902724 \\
\hline & Prometryn*Zn & -0.11334 & & & 5.363658 & 4.937874 \\
\hline & Prometryn*Ni & -0.07825 & & & 3.703073 & 3.409111 \\
\hline & $\mathrm{Cu} * \mathrm{Cd}$ & -0.09069 & & & 4.291778 & 3.951083 \\
\hline & $\mathrm{Cu} * \mathrm{~Pb}$ & -0.08152 & & & 3.857821 & 3.551575 \\
\hline & $\mathrm{Zn} * \mathrm{Ni}$ & 0.09134 & 4.322539 & 3.979402 & & \\
\hline & Total & 2.11311 & 47.928409 & & 52.071591 & \\
\hline & Dimethoate $^{b}$ & -0.03949 & & & & 1.720457 \\
\hline & Dimethoate ${ }^{*} \mathrm{Cd}^{\mathrm{b}}$ & -0.02034 & & & & 0.886151 \\
\hline & Metalaxyl ${ }^{*} \mathrm{Cu}^{\mathrm{b}}$ & 0.03760 & & 1.638116 & 1.638116 & \\
\hline & Atrazine $* \mathrm{Zn}{ }^{b}$ & 0.01273 & & 0.554607 & 0.554607 & \\
\hline & Malathion* $\mathrm{Ni}^{\mathrm{b}}$ & 0.05849 & & 2.548229 & 2.548229 & \\
\hline & Prometryn $* \mathrm{Cd}^{\mathrm{b}}$ & -0.01356 & & & & 0.590767 \\
\hline & Total $^{\text {a }}$ & & & 48.864646 & & 51.135354 \\
\hline
\end{tabular}

${ }^{a}$ The composite contamination characteristic based on the best subset regression adsorption model

${ }^{\mathrm{b}}$ The additional six significant effect factors based on the best subset regression adsorption model 


\section{Analysis of the Contribution Rate of Significant Effects of Pollutant Factors on the Fixed Effects Model}

The contribution rates of the significant main effects and second-order interaction effects to metalaxyl adsorption, calculated by the resolution $\mathrm{V} 2^{10-3}$ fractional factorial design method (Table 3), provide a good illustration of the effects of composite contamination on metalaxyl adsorption.

As shown in Table 3, contributions of $21 \%$ and $79 \%$ from the main effect and second-order interaction effects of the pollutant factor concentrations, respectively, had significant effects on adsorption of sediment to the metalaxyl, that is to say the second-order interaction effects of the pollutant factor concentrations affected the absorption of sediment to metalaxyl stronger than the main effects, though it was shown that the main effect and the second-order interaction effects of the pollutant factor concentrations had a significant effect on adsorption of sediment to metalaxyl (due to the $\mathrm{P}$ values of the main effect and the second order interaction effects were both significantly lower than the significance level of 0.05) at the previous paragraph in analysis of variance (Fig. 2). At this point, we came to a result that was further than from Fig. 2. The contributions of the main and the second-order interaction effects of the pollutant factor concentrations to significant synergistic and significant antagonistic effects on the adsorption of sediment to the metalaxyl were $47.93 \%$ and $52.07 \%$, respectively. The synergistic effects were a major control on the absorption of sediment to metalaxyl, and metalaxyl adsorption was strongly affected by the inhibitory effects of pollutant factors. The main effect and second-order interaction effects in the synergies accounted for $36.32 \%$ and $63.68 \%$, the main effect and the second-order interaction effect accounted for $6.81 \%$ and $93.19 \%$ of the antagonistic effect respectively. It can be seen that the second-order interaction effects dominates both in synergy or antagonism.

We used the best subset regression model based on the multiple linear regression model to verify the significant factors of the main effects and second-order interaction effects, and a multiple linear regression model and a best subset regression model to verify the statistical significance of the main effects and the second-order interaction effects that we obtained from the resolution $\mathrm{V} 2^{10-3}$ fractional factorial design method.

We established multiple regression adsorption models with the statistics module in Minitab to examine the degree to which adsorption of sediment to metalaxyl was influenced by interactions among the main effects and second-order interaction effects. First, we set all 10 pollutant factors and their second-order interaction terms as independent variables in the multiple linear regression models and obtained the following model structure:

Adsorption of Metalaxyl $=0.3394+0.1976$ dimethoate + 0.1208 metalaxyl -0.0050 atrazine -0.0134 malathion +0.0047 prometryn $+0.0631 \mathrm{Cd}-0.0205 \mathrm{Cu}-0.0375$
$\mathrm{Pb}-0.0174 \mathrm{Zn}-0.0204 \mathrm{Ni}-0.0769$ dimethoate 0.0015 dimethoate $*$ atrazine +0.0387 dimethoate $*$ malathion -0.0051 dimethoate $*$ prometryn +0.0158 dimethoate $* \mathrm{Cu}-0.0102$ dimethoate $* \mathrm{Cd}-0.0022$ dimethoate $* \mathrm{~Pb}-0.0414$ dimethoate $* \mathrm{Zn}-0.0281$ dimethoate $* \mathrm{Ni}-0.0185$ metalaxyl $*$ atrazine + 0.0001 metalaxyl * malathion +0.0192 metalaxyl * prometryn +0.0188 metalaxyl $* \mathrm{Cu}-0.0051$ metalaxyl $* \mathrm{Cd}-0.0540$ metalaxyl $* \mathrm{~Pb}+0.0174$ metalaxyl * $\mathrm{Zn}$ +0.039 metalaxyl $* \mathrm{Ni}-0.0486$ atrazine $*$ malathion -0.0651 atrazine * prometryn -0.051 atrazine $* \mathrm{Cu}+$ 0.0411 atrazine $* \mathrm{Cd}+0.0549$ atrazine $* \mathrm{~Pb}+0.0064$ atrazine $* \mathrm{Zn}-0.0108$ atrazine $* \mathrm{Ni}-0.0015$ malathion $*$ prometryn +0.0522 malathion $* \mathrm{Cu}-0.022$ malathion $* \mathrm{Cd}-0.0298$ malathion $* \mathrm{~Pb}-0.0448$ malathion * $\mathrm{Zn}+$ 0.0292 malathion $* \mathrm{Ni}-0.0204$ prometryn $* \mathrm{Cu}-0.0068$ prometryn $* \mathrm{Cd}+0.0309$ prometryn $* \mathrm{Zn}-0.0567$ prometryn $* \mathrm{~Pb}-0.0391$ prometryn $* \mathrm{Ni}-0.0454 \mathrm{Cu} *$ $\mathrm{Cd}-0.0408 \mathrm{Cu} * \mathrm{~Pb}-0.0165 \mathrm{Cu} * \mathrm{Zn}-0.0265 \mathrm{Cu} * \mathrm{Ni}$ $-0.0008 \mathrm{Cd} * \mathrm{~Pb}+0.0119 \mathrm{Cd} * \mathrm{Zn}-0.0075 \mathrm{Cd} * \mathrm{Ni}+$ $0.0035 \mathrm{~Pb} * \mathrm{Zn}-0.0167 \mathrm{~Pb} * \mathrm{Ni}+0.0457 \mathrm{Zn} * \mathrm{Ni}$, where “*” represents the interaction of the two variables, and indicates that the interaction between the two pollutants influenced the absorption of the target pollutant on the sediment.

Results of the goodness of fit test and the significance test ( $T$ test) for the multiple linear regression model was carried out by the resolution $\mathrm{V} 2^{10-3}$ fractional factorial design method. As for the results of the goodness of fit to Equation 1, the multiple correlation coefficient square $\left(\mathrm{R}^{2}\right)$ value was $80.29 \%$, which indicates that the independent variables of Equation 1 explained up to $80.29 \%$ of the variation associated with cadmium adsorption on the sediment. The results also show that the fitting effect of Equation 1 was relatively good. The forecast $\mathrm{R}^{2}$ obtained from repeat experiments was $59.97 \%$, which was much lower than the $\mathrm{R}^{2}(80.29 \%)$ of Equation 1, and indicates that there was some model overfitting and that some of the independent variables needed to be omitted.

The results of the $\mathrm{T}$ test for Equation 1 are shown in Table 2. The $\mathrm{P}$ value of the partial independent variable was greater than 0.05 , which shows that some of the main effects and second-order interaction effects of the 10 factors examined in this study had no significant effect on adsorption of sediment to the metalaxyl. It also showed that we needed to establish a new multiple linear regression model that could adequately characterize the composite contamination of metalaxyl and other pollutants on the sediment using the best subset regression modeling method to screen out the main effects and second-order interaction effects that had a statistically significant effect on the adsorption of metalaxyl.

When building the optimal multiple linear regression models to describe the adsorption in the composite contamination system, we established the best subset regression models using the best subset regression method and list of aliases that screened out the 


\begin{tabular}{|c|c|c|c|c|c|c|c|c|c|c|c|c|c|c|c|c|c|c|c|c|c|}
\hline $\mathrm{Cu}^{*} \mathrm{Ni}$ & & & & & & & & $\rtimes$ & $x$ & $x$ & $\rtimes$ & $x$ & $x$ & $x$ & $x$ & $x$ & $x$ & $x$ & $x$ & $x$ & $x$ \\
\hline $\mathrm{Cu}^{*} \mathrm{Zn}$ & & & & & & & & & & & & & & & & & & & & $x$ & $x$ \\
\hline \multicolumn{22}{|l|}{ Prometryn* $\mathrm{Pb}$} \\
\hline Prometryn ${ }^{*} \mathrm{Cd}$ & & & $x$ & $x$ & $x$ & $x$ & $x$ & $x$ & $x$ & $x$ & $x$ & $x$ & $x$ & $x$ & $x$ & $x$ & $x$ & $x$ & $x$ & $x$ & $x$ \\
\hline Prometryn $* \mathrm{Cu}$ & & & & & & & & & & & & & & & & $x$ & $x$ & $x$ & $x$ & $x$ & $x$ \\
\hline Malathion*Ni & & & & $x$ & $x$ & $x$ & $x$ & $x$ & $x$ & $x$ & $x$ & $x$ & $x$ & $x$ & $x$ & $x$ & $x$ & $x$ & $x$ & $x$ & $x$ \\
\hline \multicolumn{22}{|l|}{ Malathion* $\mathrm{Pb}$} \\
\hline Malathion* $\mathrm{Cd}$ & & & & & & & & & & & & & & & $x$ & $x$ & $x$ & $x$ & $x$ & $x$ & $x$ \\
\hline Malathion*Prometryn & & & & & & & & & & & & & & & & & $x$ & $x$ & $x$ & $x$ & $x$ \\
\hline Atrazine* $\mathrm{Ni}$ & & & & & & & & & & & & $x$ & $x$ & $x$ & $x$ & $x$ & $x$ & $x$ & $x$ & $x$ & $x$ \\
\hline Atrazine*Zn & $x$ & $x$ & $\times$ & $x$ & $x$ & 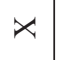 & $\rtimes$ & $\rtimes$ & $x$ & $x$ & $x$ & $x$ & $x$ & $x$ & $x$ & $x$ & $x$ & $x$ & $x$ & $x$ & $x$ \\
\hline \multicolumn{22}{|l|}{ Metalaxyl*Zn } \\
\hline \multicolumn{22}{|l|}{ Metalaxyl ${ }^{*} \mathrm{Cd}$} \\
\hline Metalaxyl $* \mathrm{Cu}$ & & & & & $x$ & $x$ & $x$ & $x$ & $x$ & $x$ & $x$ & $x$ & $x$ & $x$ & $x$ & $x$ & $x$ & $x$ & $x$ & $x$ & $x$ \\
\hline \multicolumn{22}{|l|}{ Metalaxyl*Prometryn } \\
\hline \multicolumn{22}{|l|}{ Metalaxyl*Malathion } \\
\hline Metalaxyl*Atrazine & & & & & & & & & & & $x$ & $x$ & $x$ & $x$ & $x$ & $x$ & $x$ & $x$ & $x$ & $x$ & $x$ \\
\hline \multicolumn{22}{|l|}{ Dimethoate*Ni } \\
\hline Dimethoate*Cd & & $x$ & $x$ & $x$ & $x$ & 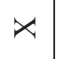 & $\rtimes$ & $\rtimes$ & $x$ & $x$ & $x$ & $x$ & $x$ & $x$ & $x$ & $x$ & $x$ & $x$ & $x$ & $x$ & $x$ \\
\hline Dimethoate* $\mathrm{Pb}$ & & & & & & & & & & & & & & & & & & & $x$ & $x$ & $x$ \\
\hline Dimethoate $* \mathrm{Cu}$ & & & & & & & & & & $x$ & $x$ & $x$ & $x$ & $x$ & $x$ & $x$ & $x$ & $x$ & $x$ & $x$ & $x$ \\
\hline \multicolumn{22}{|l|}{ Dimethoate*Prometryn } \\
\hline Dimethoate*Atrazine & & & & & & & & & $x$ & $x$ & $x$ & $x$ & $x$ & $x$ & $x$ & $x$ & $x$ & $x$ & $x$ & $x$ & $x$ \\
\hline $\mathrm{Ni}$ & & & & & & & & & & & & & & $x$ & $x$ & $x$ & $x$ & $x$ & $x$ & $x$ & $x$ \\
\hline $\mathrm{Zn}$ & & & & & & & & & & & & & $x$ & $x$ & $x$ & $x$ & $x$ & $x$ & $x$ & $x$ & $x$ \\
\hline $\mathrm{Cd}$ & & & & & & & & & & & & & & & & & & & & & \\
\hline \multicolumn{22}{|l|}{ Prometryn } \\
\hline Malathion & & & & & & & $\rtimes$ & $\rtimes$ & $x$ & $x$ & $x$ & $x$ & $x$ & $x$ & $x$ & $x$ & $x$ & $x$ & $x$ & $x$ & $x$ \\
\hline Atrazine & & & & & & & & & & & & & & & & & & $x$ & $x$ & $x$ & $x$ \\
\hline Dimethoate & & & & & & $x$ & $\rtimes$ & $\rtimes$ & $x$ & $x$ & $x$ & $x$ & $x$ & $x$ & $x$ & $x$ & $x$ & $x$ & $x$ & $x$ & $x$ \\
\hline S & 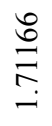 & 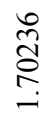 & $\begin{array}{l}\tilde{\delta} \\
\tilde{\sigma} \\
\stackrel{-}{-}\end{array}$ & $\begin{array}{l}\stackrel{8}{0} \\
: 0 \\
0 \\
\stackrel{-}{0}\end{array}$ & 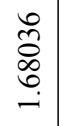 & 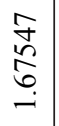 & 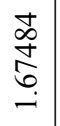 & 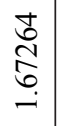 & $\begin{array}{l}\stackrel{n}{\vec{T}} \\
\hat{\sigma} \\
-\end{array}$ & 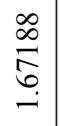 & \begin{tabular}{l}
$\hat{\sigma}$ \\
\multirow{S}{S}{} \\
$\stackrel{-}{-}$
\end{tabular} & $\begin{array}{l}\stackrel{8}{0} \\
\stackrel{2}{6} \\
\stackrel{-}{0}\end{array}$ & $\begin{array}{l}\infty \\
0 \\
0 \\
\hat{n} \\
- \\
-1\end{array}$ & 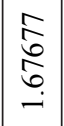 & 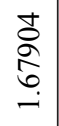 & $\begin{array}{l}0 \\
\substack{\infty \\
0 \\
0 \\
-}\end{array}$ & 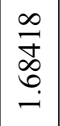 & $\begin{array}{l}0 \\
2 \\
0 \\
0 \\
0 \\
-\end{array}$ & $\begin{array}{l}\hat{\delta} \\
0 \\
0 \\
-\end{array}$ & 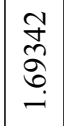 & 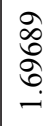 \\
\hline MallowsCp & ָั่ & $\begin{array}{l}\infty \\
\stackrel{\infty}{\infty} \\
\stackrel{\infty}{1}\end{array}$ & 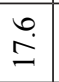 & $\vec{I}$ & $\hat{\sigma}$ & $\hat{\sigma}$ & $\stackrel{\cong}{\beth}$ & $\begin{array}{l}0 \\
\infty \\
\infty\end{array}$ & $\begin{array}{l}\ddot{\sigma} \\
\end{array}$ & $\begin{array}{l}n \\
\tilde{\sim} \\
\tilde{n}\end{array}$ & $\begin{array}{l}\infty \\
\dot{\sim} \\
\end{array}$ & ते & $\stackrel{\sim}{\dot{d}}$ & ֶָ. & 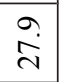 & $\stackrel{\text { iे }}{n}$ & $\frac{m}{m}$ & $\begin{array}{l}0 \\
\dot{m}\end{array}$ & $\begin{array}{l}\infty \\
\dot{m} \\
\end{array}$ & \begin{tabular}{|l|} 
\\
$\dot{0}$ \\
$\dot{\infty}$
\end{tabular} & $\begin{array}{l}+ \\
\infty \\
\infty\end{array}$ \\
\hline R-Sq(ad) & $\ddot{\ddot{r}}$ & ֶָ & $\stackrel{m}{\infty} \underset{\infty}{\infty}$ & $\stackrel{2}{2}$ & $\frac{m}{\infty}$ & $\underset{\infty}{n}$ & $\underset{\infty}{\sim}$ & 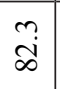 & $\begin{array}{l}\tilde{\Delta} \\
\infty\end{array}$ & $\begin{array}{l}\stackrel{i}{i} \\
\infty\end{array}$ & $\overrightarrow{\dot{d}}$ & $\frac{a}{\infty}$ & $\frac{n}{\infty}$ & $\begin{array}{l} \\
\\
\infty\end{array}$ & $\frac{\sim}{\infty}$ & $\vec{\infty}$ & $\stackrel{\dot{\infty}}{\dot{\infty}}$ & $\begin{array}{l}\infty \\
\stackrel{\gamma}{2}\end{array}$ & $\overrightarrow{2}$ & $\begin{array}{c}n \\
\infty \\
\infty\end{array}$ & $\stackrel{n}{\gtrless}$ \\
\hline $\mathrm{R}-\mathrm{Sq}$ & $\stackrel{n}{i}$ & 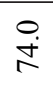 & $\stackrel{?}{2}$ & \begin{tabular}{l}
\multirow{\infty}{\infty}{} \\
$\infty$
\end{tabular} & $\stackrel{\vec{\gamma}}{ }$ & $\frac{\vec{\infty}}{\infty}$ & $\overrightarrow{\widetilde{i}}$ & $\vec{\infty}$ & $\begin{array}{l}\infty \\
\infty \\
\infty\end{array}$ & $\begin{array}{l}\stackrel{+}{\Phi} \\
\dot{\infty}\end{array}$ & $\begin{array}{l}\stackrel{े}{\infty} \\
\dot{\infty}\end{array}$ & $\begin{array}{l}\vec{b} \\
\ddot{\infty}\end{array}$ & $\vec{\infty}$ & $\vec{\infty}$ & గ్రి & $\begin{array}{l}0 \\
\infty \\
\infty\end{array}$ & $\begin{array}{l}\infty \\
\dot{\infty} \\
\dot{\infty}\end{array}$ & $\begin{array}{l}\grave{\infty} \\
\infty\end{array}$ & $\overrightarrow{\vec{\infty}}$ & $\begin{array}{l}2 \\
\stackrel{2}{\infty}\end{array}$ & $\underset{\infty}{\dot{\alpha}}$ \\
\hline Vars & - & $\mathrm{N}$ & $m$ & $\nabla$ & $n$ & 6 & $r$ & $\infty$ & $a$ & 으 & $=$ & $\simeq$ & $m$ & \pm & $\because$ & $\stackrel{0}{-}$ & $=$ & $\infty$ & 2 & ก & $\bar{N}$ \\
\hline
\end{tabular}




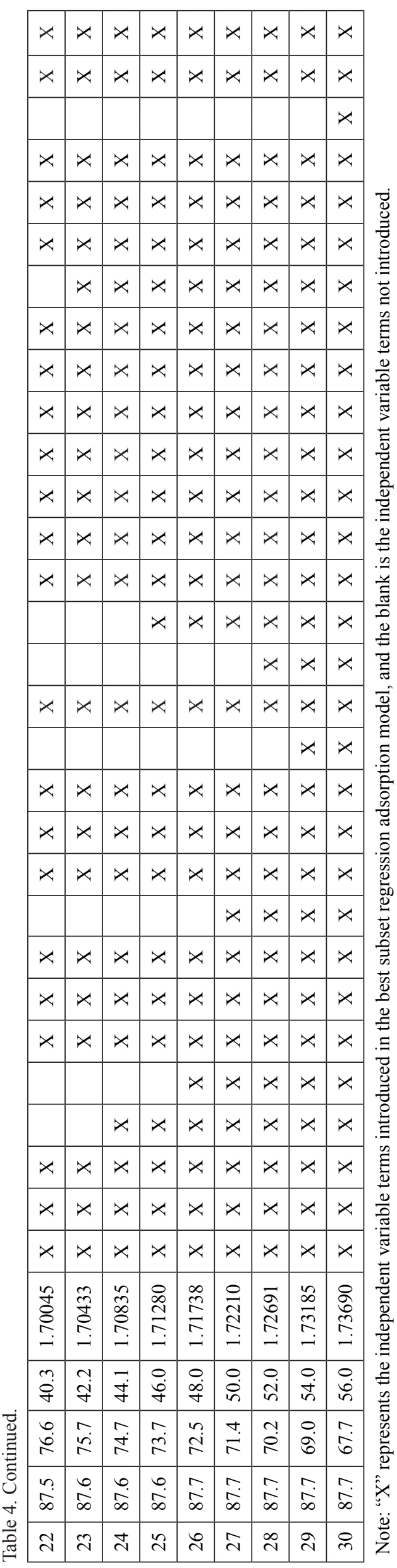

independent variables in the multiple linear regression adsorption models (Table 4). We had two criteria for this model: (1) the R-squared value was at a maximum, and (2) Mallows' Cp (used to estimate the mean square error) was as low as possible .

The $8^{\text {th }}$ model, with dimethoate as the main effect, and dimethoate*cadmium, metalaxyl* ${ }^{*} \mathrm{Cu}$, atrazine*zinc, malathion*nickel, and prometryn*cadmium as the second-order interaction effects, was the best subset regression adsorption model because it had the lowest Mallows' $\mathrm{Cp}$, and its adjusted $\mathrm{R}^{2}$, at more than $80 \%$, was the highest (Table 4). The adsorption of metalaxyl in the model was described as follows:

Adsorption of metalaxyl $=0.3394+0.1208$ metalaxyl +0.0631 copper $-0.0375 \mathrm{~Pb}-0.0769$ dimethoate * metalaxyl +0.0387 dimethoate $*$ malathion -0.0414 dimethoate * $\mathrm{Zn}-0.0540$ metalaxyl * $\mathrm{Pb}+0.0390$ metalaxyl $* \mathrm{Ni}-0.0486$ atrazine $*$ malathion -0.0651 atrazine * prometryn -0.0510 Atrazine $* \mathrm{Cu}+0.0411$ atrazine $* \mathrm{Cd}+0.0549$ atrazine $* \mathrm{~Pb}+0.0522$ malathion $* \mathrm{Cu}-0.0448$ malathion $* \mathrm{Zn}-0.0567$ prometryn $* \mathrm{Zn}-0.0391$ prometryn $* \mathrm{Ni}-0.0454 \mathrm{Cu} * \mathrm{Cd}-$ $0.0408 \mathrm{Cu} * \mathrm{~Pb}+0.0457 \mathrm{Zn} * \mathrm{Ni}-0.0198$ dimethoate -0.0102 dimethoate $* \mathrm{Cd}+0.0188$ metalaxyl $* \mathrm{Cu}+$ 0.0064 atrazine $* \mathrm{Zn}+0.0292$ malathion $* \mathrm{Ni}-0.0068$ prometryn $* \mathrm{Cd}$.

When compared with the resolution $\mathrm{V} 2^{10-3}$ fractional factorial design method, the number of statistically significant effect terms of Equation 2 increased by six, namely the interactions between dimethoate, dimethoate * cadmium, metalaxyl * copper, atrazine * zinc, malathion * nickel, and prometryn*cadmium. The contributions of the synergistic effects and antagonistic effects with the additional six factors are shown in Table 3.

As shown in Table 3, the fact that the contributions of the synergistic and antagonistic effects for the additional six factors listed above for the fixed effects model and those for the fixed effects model in the resolution $\mathrm{V} 2^{10-3}$ fractional factorial design method were not significantly different, confirming that the results simulated by the fixed effects model for resolution $\mathrm{V} 2^{10-3}$ fractional factorial design method were accurate.

\section{Analysis of the Difference between Resolution $\mathrm{V} 2^{10-3}$ and IV $2^{10-5}$ Methods}

The resolution $\mathrm{V} 2^{10-3}$ fractional factorial design method estimated the freedom of the second-order effect at 45 , and was able to remove the confounding effects of the second-order interaction effects. In contrast, the resolution IV $2^{10-5}$ fractional factorial design method estimated 39 freedoms. The resolution $\mathrm{V} 2^{10-3}$ fractional factorial design comprised 17 second-order interaction effect terms that had a significant effect on absorption of sediment to metalaxyl. Only three of the second-order interaction effects from the resolution IV $2^{10-5}$ fractional factorial design were significant, namely (in decreasing order) atrazine * copper, prometryn * copper, and 
lead * nickel. The fact that the resolution IV $2^{10-5}$ fractional factorial design method had 14 fewer significant second-order interaction effects than the resolution $\mathrm{V} 2^{10-3}$ method shows that the resolution IV $2^{10-5}$ fractional factorial design did not provide enough information to distinguish the aliases of the secondorder interaction effects. The second-order interaction effects associated with the target pollutant metalaxyl in the resolution $\mathrm{V} 2^{10-3}$ fractional factorial design method were not aliased. The resolution $\mathrm{V} 2^{10-3}$ fractional factorial design therefore eliminated the aliasing between the second-order interaction effects.

In recent studies, including molecule design [31], the exploration of factors affecting drug properties [32], and the adsorption of heavy mental/pesticides $[33,34]$, have already used a fractional factorial design with a resolution of $\mathrm{V}$ to explore the main effects and interaction effects between the different factors. As for the research of competitive adsorption of heavy mental and pesticides, it was mostly among different heavy metals or different pesticides. Going forward, it has been documented that when heavy metals and pesticides coexisted, interactions occurred in coexisting systems, which are mainly characterized by competitive adsorption in the soil and sediment environment, chelation, interactions by changing environmental conditions, and the process of absorption and migration in plants.

For example, the heavy metal $\mathrm{Cu}$ can reduce the adsorption of humic acid to propofol, probably because $\mathrm{Cu}$ and propofol can bind to the carboxyl and phenolic groups of humic acid, competing for the same adsorption site [35]; $\mathrm{Zn}, \mathrm{Cu}$ and glyphosate also interact by competing for the same site [36, 37]. Some groups in the glyphosate molecule can easily combine with metal ions to form ligands, which cause heavy metals to complex with pesticides, changing the migration and transformation of them in the environment, thus affecting the content and adsorption of them in the medium [38]. The complexation of $\mathrm{Cu}$ with glyphosate reduced the adsorption of montmorillonite to glyphosate by [39], and their combination can also reduce the adsorption of fulvic acid to glyphosate [40]. In another medium soil, some researchers had found that the stronger the complex formation of $\mathrm{Cu}$ and glyphosate, the easier it is to be adsorbed by the soil, and the amount of glyphosate adsorbed by the soil increased [37].

In $2018 \mathrm{Chu}$ [33] identified the main effects and second-order interaction effects of pollutants (copper, cadmium, lead, zinc, nickel, dimethoate, metalaxyl, atrazine, malathion, and prometryn) on metals adsorption onto sediments, to reveal the relationships between metal ion characteristics and the effects of pollutants on metals adsorption, while the relationships between adsorption characteristics and effects in the above pollutants on pesticides adsorption were revealed by Wang et al. [34].

Compared with the above two studies, this study focused on contrastive analysis to IV and V. As shown in Table 3 , for the resolution IV $2^{10-5}$ fractional factorial design method, the contributions of the significant main effects and second-order interaction effects of the pollutant factor concentrations on absorption of sediment to metalaxyl were $26 \%$ and $74 \%$, respectively. This shows that as was the case for the resolution IV $2^{10-3}$ method (for which the contributions of the significant main effects and second-order interaction effects of the pollutant factor concentrations on absorption of sediment to metalaxyl were $21 \%$ and $79 \%$, respectively), the second-order effects had most influence on absorption of sediment to metalaxyl for the resolution IV $2^{10-5}$ method. Also, the same as the research by Wang et al. [33], second-order interaction effects were primarily responsible for metalaxyl (the rates of contributions were $79.05 \%$ ) in the pesticide/ heavy metals coexisting sediment system. There was also some overlap between the main effects and secondorder interaction effects for the resolution $\mathrm{V} 2^{10-3}$ and resolution IV $2^{10-5}$ methods that had a significant effect on metalaxyl adsorption on the sediment, namely when the main effect was copper and the second-order interaction effect was atrazine*copper. Furthermore, the atrazine*copper second-order interaction effect had a significant synergistic effect absorption of sediment to metalaxyl for the resolution $\mathrm{V}^{10-3}$ and the resolution IV $2^{10-5}$ methods.

In Table 3, for the resolution IV $2^{10-5}$ fractional factorial design method, the sum of the contributions of the main effects and the second-order interaction effects of the pollutant factor concentrations with significant synergistic effects and significant antagonistic effects on metalaxyl adsorption on the sediment were $19.60 \%$ and $80.40 \%$, respectively. This differed from the resolution $\mathrm{V} 2^{10-3}$ fractional factorial design method (for which the same contributions were 47.93\% and $52.07 \%$, respectively). The contribution of the significant antagonistic effects to absorption of sediment to metalaxyl was much greater than the contribution of the significant synergistic effects for the resolution IV $2^{10-5}$ fractional factorial design method. The results show that the sum of the contribution of the main effects and second-order interaction effects of the pollutant factor concentrations with significant synergistic effects on the adsorption of metalaxyl on the sediment was $28.33 \%$ lower $(19.60 \%$ compared with $47.93 \%$ ) for the resolution $\mathrm{V}^{10-3}$ method than for the resolution IV $2^{10-5}$ method, and that these effects were underestimated by the resolution IV $2^{10-5}$ fractional factorial design method. Comparison of the resolution $\mathrm{V}^{10-3}$ and the resolution IV $2^{10-5}$ methods showed that the sum of the contribution of the main effects and second-order interaction effects of the pollutant factor concentrations with significant antagonistic effects on adsorption of metalaxyl on the sediment was $28.33 \%$ higher $(52.07 \%$ compared with $80.40 \%)$ for the resolution IV $2^{10-5}$ method, which indicates that the resolution IV $2^{10-5}$ fractional factorial design method overestimated these effects. 
The problems of overestimation and underestimation of the contributions of the main and second-order interactions effects associated with the resolution IV $2^{10-5}$ method were therefore solved by the resolution $\mathrm{V} 2^{10-3}$ fractional factorial design method. This example serves to highlight the complexity of the composite pollution mechanisms between pesticides and heavy metals.

\section{Differences between the Mechanisms of Metalaxyl and Cadmium Adsorption in the Resolution V $2^{10-3}$ Fractional Factorial Design Method}

As already reported by $\mathrm{Gu}$ et al. [28], when cadmium was the target pollutant, the freedom of the secondorder effect estimated by the resolution V $2^{10-3}$ fractional factorial design method increased from 21 (obtained for the resolution IV $2^{10-5}$ method) to 45 . When metalaxyl was the target pollutant, the freedom of the secondorder effect increased from 36 for the resolution IV $2^{10-5}$ method to 45 for the resolution $\mathrm{V} 2^{10-3}$ method.

In the heavy metal/pesticide combined system, the contributions of the main and second-order effects to $\mathrm{Cd}$ adsorption for the resolution $\mathrm{V} 2^{10-3}$ fractional factorial design method were $87 \%$ and $13 \%$, respectively. In this study, the contribution rates of the main and the second-order interaction effects to metalaxyl adsorption for the resolution $\mathrm{V} 2^{10-3}$ fractional factorial design method were $21 \%$ and $79 \%$, respectively. In the system with only heavy metals, the contribution of the significant main effects to metalaxyl adsorption was lower than the contribution from the significant secondorder interaction effects. In the heavy metal/pesticide combined system, the second-order interaction effects had the most influence on metalaxyl absorption on sediment, while the main effects had the most influence on the absorption of sediment to the cadmium. The sediment therefore had a lower capacity to absorb metalaxyl than cadmium.

In the heavy metal/pesticide combined system, the sum of the contributions of the main effects and secondorder interaction effects with significant synergistic and significant antagonistic effects on the absorption of sediment to the cadmium were $49.80 \%$ and $50.16 \%$, respectively, and the sum of the contribution rates of the same effects to metalaxyl adsorption on the sediment were $47.93 \%$ and $52.07 \%$, respectively, for the resolution $\mathrm{V} 2^{10-3}$ fractional factorial design method. The balance between the significant synergistic and significant antagonistic effects for adsorption of metalaxyl and heavy metals on sediment was also different. The significant synergistic and significant antagonistic effects on the absorption of sediment to the cadmium reached a state of equilibrium; that is, the synergistic and antagonistic effects cancelled each other out. The contribution of the main effects and secondorder interaction effects with antagonistic effects on metalaxyl adsorption on sediment was higher than the contribution of the synergistic effects, which shows that the antagonistic effects controlled absorption of sediment to metalaxyl. We suggest that metalaxyl adsorption is less stable than cadmium adsorption.

The above comparisons show that sediment has a lower capacity to adsorb pesticides than heavy metals, and that pesticide adsorption is also less stable than heavy metal adsorption in a pesticide/heavy metal combined system.

\section{Conclusions}

(1) In this study, we used a fixed effects model to screen out the significant $(\mathrm{P}=0.05)$ main effects and the second-order interaction effects on absorption of sediment to metalaxyl using the resolution $\mathrm{V} 2^{10-3}$ fractional factorial design method. We also estimated and characterized the effect of composite contamination on metalaxyl adsorption. Using the multiple linear regression model and the optimal subset regression model, we verified that the main effects and second-order interaction effects from the resolution $\mathrm{V} 2^{10-3}$ fractional factorial design method were statistically significant.

(2) This is the first study that has considered metalaxyl as the target pollutant. Comparison of the results from the resolution $\mathrm{V} 2^{10-3}$ and the resolution IV $2^{10-5}$ fractional factorial design methods for a pesticide/heavy metal composite contamination system showed that the resolution $\mathrm{V} 2^{10-3}$ method was able to identify all the aliases of the second-order interaction effects associated with metalaxyl, and also solved the issues associated with overestimating and underestimating the contributions of the main and second-order effects to the synergistic and antagonistic effects on adsorption associated with the resolution IV $2^{10-5}$ method. We also provided new information about the differences in the adsorption characteristics of metalaxyl and cadmium in the same system.

(3) We have demonstrated that this method can be used to study the main effect and second-order interactions of other pollutants, and that the interactions that occur between pesticides and heavy metals in a combined pollutant system can be identified.

The results of this study will provide information about the mechanisms that govern combined pollution from pesticide and heavy metal compounds. It also provides a theoretical basis for revealing the composite pollution between different pollutants in the water or sediment environment. However, in this paper only the pesticide metalaxyl was used as the target pollutant, and we explored the effects of pesticides and heavy metals concentrations in a composite contamination system on adsorption of sediment to simplex metalaxyl. As for the next research direction of pesticides/heavy metal compound pollution, it can be used as a research object for all pesticide heavy metals in the composite contamination system instead of the simplex pesticide or 
heavy metal, and explore the joint adsorption mechanism of each pesticide heavy metal in the composite system.

\section{Acknowledgements}

This work was supported by the Fundamental Research Funds for the Central Universities in 2013 (grant No. JB2013146): Study on Toxicity Control of PBDEs Based on Quantum Chemistry and QSAR Model; and supported by the Fundamental Research Funds for the Central Universities in 2017 (grant No. 2017XS058): Study on Enhancement of Vibrational Spectra by Derivation of Phthalic Acid Esters using Pharmacophore Model.

\section{Conflict of Interest}

The authors declare no conflict of interest.

\section{References}

1. UDEIGWE T. K., TEBOH J. M., EZE P. N. Implications of $\mathrm{Pb}$ crop production practices on environmental quality and human health. J. Environ. Manage. 151, 267, 2015.

2. CONCAS A., ARDAU C., CRISTINI A. Mobility of heavy metals from tailings to stream waters in a mining activity contaminated site. Chemosphere. 63 (2), 244, 2006.

3. SUN Z.G., WANG L.H., ZHOU Q. Effects and mechanisms of the combined pollution of lanthanum and acid rain on the root phenotype of soybean seedlings. Chemosphere. $\mathbf{9 3}$ (2), 344, 2013

4. ARIAS-ESTÉVEZ M., LÓPEZ-PERIAGO E., MARTÍNEZ-CARBALLO E., SIMAL-GÁNDARA J., MEJUTO J. C., GARCÍA-RÍO L. The mobility and degradation of pesticides in soils and the pollution of groundwater resources. Agr. Ecosyst. Environ. 123 (4), 247, 2008.

5. LI Y.Y., WANG H.B., WANG H.J., YIN F., YANG X.Y., HU Y.J. Heavy metal pollution in vegetables grown in the vicinity of a multi-metal mining area in Gejiu, China, total concentrations, speciation Analysis, and health risk. Environ. Sci. Pollut. R. 21, (21), 12569, 2014.

6. SHARIF A., ASHRAF M., ANJUM A.A., JAVEED A., ALTAF I., AKHTAR M.F., ABBAS M., AKHTAR B., SALEEM A. Pharmaceutical wastewater being composite mixture of environmental pollutants may be associated with mutagenicity and genotoxicity. Environ. Sci. Pollut. R. 23, 2813, 2016.

7. QUINTEROS E., RIBÓ A., MEJÍA R., LÓPEZ A., BELTETON W., COMANDARI A., ORANTES C. M., PLEITES E. B., HERNÁNDEZ C. E., LÓPEZ D. L. Heavy metals and pesticide exposure from agricultural activities and former agrochemical factory in a salvadoran rural community. Environ. Sci. Pollut. Res. 24, 1662, 2017.

8. LI Y., WANG X.L., WANG Y., DONG D.M., ZHANG H. P., LI Q.S., LI X.C. Comparison of $\mathrm{Pb}$ and $\mathrm{Cd}$ adsorption to the surface coatings and surficial sediments collected in Xianghai Wetland. J. Environ. Sci. 17 (1), 126, 2005.

9. MARGOUM C., MALESSARD C., GOUY V. Investigation of various physicochemical and environmental parameter influence on pesticide sorption to ditch bed substratum by means of experimental design. Chemosphere. 63, 1835, 2006.

10. PALMA P., PALMA V.L., MATOS C., FERNANDES R.M., BOHN A., SOARES A.M.V.M., BARBOSA I.R. Assessment of the pesticides atrazine, endosulfan sulphate and chlorpyrifos for juvenoid-related endocrine activity using Daphnia magna. Chemosphere. 76 (3), 335, 2009.

11. ZVINAVASHE E., DU T.T., GRIFF T., BERG H.H.J. V.D., SOFFERS A.E.M.F., VERVOORT J., MURK A.J., RIETJENS I.M.C.M. Quantitative structureactivity relationship modeling of the toxicity of organothiophosphate pesticides to Daphnia magna and Cyprinus carpio. Chemosphere. 75 (11), 1531, 2009.

12. LI S.S., GAO Q., WANG X.L., LI Y. Using multiple regression adsorption models to estimate $\mathrm{Zn}$ and $\mathrm{Cu}$ adsorptions onto $\mathrm{Fe}$ oxides, $\mathrm{Mn}$ oxides, organic materials and their blends in surficial sediments. Fresen. Environ. Bull. 19 (8), 1466, 2010.

13. WONG K.W., YAP C.K., NULIT R., HAMZAH M.S., CHEN S.K., CHENG W.H., KARAMI A., AL-SHAMI S.A. Effects of anthropogenic activities on the heavy metal levels in the clams and sediments in a tropical river. Environ. Sci. Pollut. R. 24 (1), 116, 2017.

14. GUO J., YUE T.L., LI X.T., YUAN Y.H. Heavy metal levels in kiwifruit orchard soils and trees and its potential health risk assessment in Shanxi, China. Environ. Sci. Pollut. R. 23 (14), 14560, 2016.

15. VONGDALA N., TRAN H.D., XUAN T.D., TESCHKE R., KHANH T.D. Heavy Metal Accumulation in Water, Soil, and Plants of Municipal Solid Waste Landfill in Vientiane, Laos. Int. J. Environ. Res. Public Health, 16 (1), 22, 2019.

16. KODA E., MISZKOWSKA A., SIECZKA A., OSIŃSKI P. Heavy metals contamination within restored landfill site in Poland. Environ. Geotech. 2018. (https://doi.org/10.1680/ jenge.18.00031)

17. LI Y., GAO Q., WANG X.L., DONG D.M., WANG A. Synergetic and antagonistic effects of cadmium on the adsorption of atrazine in the surficial sediments. Chem. Res. Chinese. U. 25 (2), 155, 2009.

18. GAO Q., WANG A., LI Y. Combined effect of co-existing heavy metals and organophosphate pesticide on adsorption of atrazine to river sediments. Korean. J. Chem. Eng. 28, (5), 1200, 2011.

19. YANG C.J., ZHOU Q.X., WEI S.H., HU Y.H., BAO Y.Y. Chemical-assisted phytoremediation of Cd-PAHs contaminated soils using Solanum nigrum L. Int. J. Phytoremediat. 13 (8), 818, 2011.

20. WU L.H., LI Z., HAN C.L., LIU L., TENG Y., SUN X.H., PAN C., HUANG Y.J., LUO Y.M., CHRISTIE P. Phytoremediation of soil contaminated with cadmium, copper and polychlorinated biphenyls. Int J. Phytoremediat. 14 (6), 570, 2012.

21. DIAZRAVINA M., BAATH E. Development of metal tolerance in soil bacterial communities exposed to experimentally increased metal levels. Appl. Environ. Microb. 62 (8), 2970, 1996.

22. GILLER K.E., WITTER E., MCGRATH S. P. Toxicity of heavy metals to microorganisms and microbial processes in agricultural soils, a review. Soil. Biol. Biochem. 30 (10), 1389, 1998

23. WANG F., YAO J., SI Y., CHEN H.L., RUSSEL M., CHEN K., QIAN Y.G., ZARAY G., BRAMANTI E. Shorttime effect of heavy metals upon microbial community activity. J. Hazard. Mater. 173 (1), 510, 2010. 
24. WANG X. Q., HE M.C., XIE J., LU X.F. Heavy metal pollution of the world largest antimony mine-affected agricultural soils in Hunan province (China). J. Soil. Sediment. 10 (5), 827, 2010.

25. LIU T.F., WANG T., SUN C., WANG Y.M. Single and joint toxicity of cypermethrin and copper on Chinese cabbage (pakchoi) seeds. J. Hazard. Mater. 163, 344, 2009.

26. CHIRAKKARA R.A., CAMESELLE C., REDDY K.R. Assessing the applicability of phytoremediation of soils with mixed organic and heavy metal contaminants. Rev. Environ. Sci. Bio. 15 (2), 299, 2016.

27. LI Y., WANG M., ZHANG C., GAO Q. Law of competitive adsorption of zinc and variety of pollutants based on fractional factorial design. Journal of Central South University (Science and Technology). 5 (44), 2151, 2013 [In Chinese].

28. GU W.W., CHENG B.C., LI Y. Interference adsorption of cadmium with a variety of pollutants in sediments based on fractional factorial design (resolution V). Pol. J. Environ. Stud. 26 (1), 47, 2017.

29. ECHEVERRÍA J.C., MORERA M.T., MAZKIARÁN C., GARRIDO J.J. Competitive sorption of heavy metal by soils. Isotherms and fractional factorial experiments. Environ. Pollut. 101 (2), 275, 1998.

30. ZHANG F.J., OU X.X., CHEN S., RAN C.Q., QUAN X. Competitive adsorption and desorption of copper and lead in some soils of north China. Frontiers of Environmental Science and Engineering in China. 6 (4), 484, 2012 [In Chinese].

31. CHU Z.H., GU W.W., LI Y. Designing modified polybrominated diphenyl ether BDE-47, BDE-99, BDE100, BDE-183, and BDE-209 molecules with decreased estrogenic activities using 3D-QSAR, pharmacophore models coupled with resolution $\mathrm{V}$ of the $2^{10-3}$ fractional factorial design and molecular docking. J. Hazard. Mater. 364, 151, 2019.
32. EL-HELALY S.N., HABIB B.A., EL-RAHMAN M.K. A. Resolution $\mathrm{V}$ fractional factorial design for screening of factors affecting weakly basic drugs liposomal systems. Eur. J. Pharm. Sci. 119, 2018.

33. CHU Z. H., GU W. W., LI Y Adsorption Mechanism of Heavy Metals in Heavy Metal/Pesticide Coexisting Sediment Systems through Factional Factorial Design Assisted by 2D-QSAR Models. Pol. J. Environ. Stud. 27 (6), 2451, 2018.

34. WANG X.L., LI Q., LI M.H., LI Y. Interference adsorption mechanisms of dimethoate, metalaxyl, atrazine, malathion and prometryn in a sediment system containing coexisting pesticides/heavy metals based on fractional factor design(resolution V) assisted by 2d-qsar. Chem. Res. Chinese U. 34, (3), 397, 2018.

35. XU Z.H., HUANG M.X., GU Q.B., WANG Y., CAO Y.Z., DU X.M., XU D.P., HUANG Q., LI F.S. Competitive sorption behavior of copper (II) and herbicide propisochlor on humic acids. J. Colloid Interf. Sci. 287, 422, 2005.

36. WANG Y.J., ZHOU D.M., SUN R.J., JIA D.A., ZHU H.W., WANG S.Q. Zinc adsorption on goethite as affected by glyphosate. J. Hazard. Mater., 151, 179, 2008.

37. MORILLO E., UNDABEYTIA T., MAQUEDA C., RAMOS A. Glyphosate adsorption on soils of different characteristics: Influence of copper addition. Chemosphere. 40 (1), 103, 2000.

38. MORILLO E., UNDABEYTIA T., MAQUEDA C., RAMOS A. The effect of dissolved glyphosate upon the sorption of copper by three selected soils. Chemosphere. 47, 747, 2002.

39. MORILLO E., UNDABEYTIA T., MAQUEDA C. Adsorption of glyphosate on the clay mineral montmorillonite: effect of $\mathrm{Cu}$ (II) in solution and adsorbed on the mineral. Environ. Sci. Technol. 31, 3588, 1997.

40. MAQUEDA C., MORILLO E., UNDABEYTIA T., MARTÍN F. Sorption of glyphosate and $\mathrm{Cu}$ (II) on a natural fulvic aced complex: mutual influence. Chemosphere., 37 (6), 1063, 1998. 
